\title{
Balzac avant Balzac sous la direction de Claire Barel- Moisan et José-Luis Diaz
}

\section{Marco Stupazzoni}

\section{Q OpenEdition}

1 Journals

\section{Edizione digitale}

URL: http://journals.openedition.org/studifrancesi/8975

DOI: $10.4000 /$ studifrancesi.8975

ISSN: 2421-5856

\section{Editore}

Rosenberg \& Sellier

\section{Edizione cartacea}

Data di pubblicazione: 1 octobre 2008

Paginazione: 475

ISSN: 0039-2944

\section{Notizia bibliografica digitale}

Marco Stupazzoni, «Balzac avant Balzac sous la direction de Claire Barel-Moisan et José-Luis Diaz»,

Studi Francesi [Online], 155 (LII | II) | 2008, online dal 30 novembre 2015, consultato il 12 janvier 2021. URL: http://journals.openedition.org/studifrancesi/8975; DOI: https://doi.org/10.4000/studifrancesi. 8975

Questo documento è stato generato automaticamente il 12 janvier 2021.

\section{(c) (1)}

Studi Francesi è distribuita con Licenza Creative Commons Attribuzione - Non commerciale - Non opere derivate 4.0 Internazionale. 


\title{
Balzac avant Balzac sous la direction de Claire Barel-Moisan et José-Luis Diaz
}

\author{
Marco Stupazzoni
}

\section{NOTIZIA}

Balzac avant Balzac sous la direction de Claire BAREL-MOISAN et José-Luis DIAZ, Groupe international de recherches balzaciennes, Saint-Cyr-sur-Loire, Christian Pirot éditeur, 2006 («Collection Balzac»), pp. 199.

1 Per lungo (e troppo) tempo «annulée par cette double déconsidération, la sienne et celle de la critique», scrive José-Luis Diaz (Devenir Balzac, pp. 7-19; cit. p. 10) la produzione romanzesca giovanile di Balzac ha suscitato, ma soltanto in tempi abbastanza recenti (a partire, grosso modo, dalla seconda metà del Novecento) l'interesse della critica internazionale divenendo allo stesso tempo accessibile al grande pubblico per merito di lodevoli quanto intelligenti ed opportune iniziative editoriali. Con $\mathrm{i}$ «premiers romans», siamo di fronte ad un laboratorio di invenzione e di scrittura sorprendentemente ricco e dinamico: «Nous sommes face à une oeuvre, osserva Diaz, [...] face à une planète littéraire [...] qui se meut dans un tout autre chronotope [...] et qui mérite bien un travail systématique d'exploration» (p.11). Questa raccolta di studi è strutturata secondo un criterio essenzialmente tematico.

2 Nicole Mozet (Que savons-nous de l'enfance de Balzac? (1799-1814), pp. 21-27) affronta il tema dell'infanzia dello scrittore dal punto di vista biografico, oltre che storicogeografico: sono, in particolare, $\mathrm{i}$ «grands textes de la Touraine» (p. 21) ad attirare l'attenzione dell'autore in quanto testimonianze preziose «de cette mémoire vivace» legata ad un'infanzia vissuta tra «l'enchevêtrement des destinées individuelles» e «la brutalité de l'histoire collective» (p. 26). Marie-Bénédicte DiETHELM (Jardin des origines et origine du jardin: le paradis perdu du jeune Balzac, pp. 29-45) considera il tema dell'infanzia 
come elemento fantasmatico legato alla visione di una «tendresse idéale au sein d'un lieu idyllique» (p. 30) che lo scrittore ricompone a posteriori, alla creazione di un Eden immaginario «né de la souffrance et de la frustration» (p. 43).

José-Luis Diaz (Imaginaires littéraires du jeune Balzac (1818-1822), pp. 47-62) focalizza il suo interesse sulla evoluzione del giovane Balzac «à travers les divers scénarios auctoriaux qu'il adopte tour à tour, choix qui se trouvent liés [...] à deux autres aspects de son activité: ses choix génériques et stylistiques, d'une part, ses choix de carrière, de l'autre» (p. 47). Caroline RAULET-MARCEL (Les romans de jeunesse de Balzac: une représentation problématique de l'auctorialité ou le jeu de piste avec le lecteur, pp. 63-78) pone l'accento sulla questione della paternità (peraltro negata) dei "romans de jeunesse" balzachiani vista in rapporto con le «différentes figures d'écrivains dans les romans» $\mathrm{e}$ ai diversi tipi di relazione tra lo scrittore («insaisissable», p. 65) e i suoi lettori.

4 Joëlle GLEIzE (Horace de Saint-Aubin, "triste héros de préface", pp. 79-93) analizza l'uso degli pseudonimi nelle prefazioni dei romanzi giovanili soffermandosi, più particolarmente, sulle «stratégies d'écriture et de publication» legate all'impiego dello pseudonimo Horace de Saint-Aubin, che si rivela «hautement révélateur des hésitations et contradictions du Balzac avant Balzac» (p. 80). Christine MARCANDIER (Horace de SaintAubin, de la figure à la fiction. L'exemple du «Centenaire», pp. 95-107) ritiene che, ne Le Centenaire, Balzac intende «voir en quoi la pseudonymie [...] doit être analysée comme une stratégie narrative, comme un pré-texte, exhibant une fiction centre et objet du roman» (p. 97).

5 Isabelle Michelot (De l'essai à l'échec: les errances d'un rêveur de théâtre, pp. 109-121) sottolinea la singolarità e la rilevanza dei primi "essais dramatiques" balzachiani e osserva che «l'école de l'écriture théâtrale est fondamentale pour la génétique de l'écriture du père de la future Comédie humaine, tant sur le plan des matrices imaginaires que sur celui de la composition du drame» (p. 109). Olivier BARA (Le champ théâtral sous la Restauration: essais dramatiques et stratégies de conquête du jeune Balzac, pp. 123-138) colloca i primi "essais dramatiques" di Balzac nel contesto più ampio della produzione teatrale della Restaurazione. L'autore interpreta queste prime «tentatives théâtrales de Balzac [...] par l'environnement institutionnel et esthétique qui les a, en partie, motivées et finalement [...] rejetées» (p. 124).

6 Aude Déruelle (“L'Excommunié" ou les apories du roman historique, pp. 139-152) studia i rapporti tra romanzo storico (come genere) e L'Excommunié (opera che per molti aspetti costituisce un plagio del Quentin Durward di W. Scott) considerati sotto la prospettiva delle relazioni tra finzione romanzesca e verità storica. Claire BAREL-MOISAN (Les sciences au risque de la fiction, pp.153-169) esamina il ruolo della scienza e degli uomini di scienza nei romanzi giovanili: in particolare, ne Le Centenaire, «le jeune Balzac a poussé sa méditation sur le statut et le pouvoir des sciences ainsi que sur la frontière mouvante les séparant du fantastique» (p. 153).

7 Nicole Mozet (Et après? Postface, pp. 171-173) sottolinea la continuità, in Balzac, tra «les extraordinaires stratégies de la maturité» e «les explorations un peu brouillonnes des années vingt» (p.11): lo scrittore, osserva bene l'autore, «a pu être en même temps [...] l'écrivain des réemplois et encore, tel Vautrin, l'acteur aux mille facettes et aux incessantes "incarnations" aussi bien dans sa jeunesse que dans sa maturité» (p. 173). I preziosi contributi di Marie-Bénédicte Diethelm, «Éléments bibliographiques» 
(pp.175-181), «Chronologie (1810-1828)» (pp.183-197), completano e chiudono le pagine del volume. 